\title{
Body Awareness, Nutrition and Health of AdolescentsAttending Physical Education Lessons
}

\author{
Inci Kesilmișis, Turhan Toros ${ }^{2}$ \\ ${ }^{1}$ Department of Physical Education and Sports, Osmaniye Korkut \\ Ata University, Osmaniye, Turkey \\ ${ }^{2}$ Faculty of Sports Sciences, Department of Training Sciences, \\ Mersin University, Mersin, Turkey \\ Study Area: Osmaniye, Turkey \\ Coordinates: $37^{\circ} 04^{\prime} 30^{\prime \prime} \mathrm{N} 36^{\circ} 15^{\prime} \mathrm{oo} " \mathrm{E}$
}

Key words: Sport training, Sensoriomotor, Sports techniques, Sports skill

The study was approved by the Ethics Committee of the Osmaniye Korkuta Ata University (2020/20/5-13382).

\section{Introduction:}

Physical activity supports positive cognitive outcomes in young children, including applied lessons and academic performance (CDC, 2010; Khan et al., 2014). It is an important window to gain habits from childhood to develop healthy physical activity behaviors because regular physical activity extends from childhood to adulthood (CDC, 2018). Physical education lessons are considered as an effective environment for encouraging participation of physical activity in children as they provide an opportunity to reach a large number of children (Dobbins et al., 2009; Marshall \& Hardman, 200o). Movements in physical education lessons, body and structure functions to improve, psychomotor development, physical fitness, physical, social, sensory development of the control of the joints and muscles to provide a balance and both in school and after school life to use their energy more sparingly is a system of activities that teach hands and feet to move in a coordinated manner (Haywood, 1991). Physical education lessons that

\section{Abstract}

We aimed to study the correlation between body awareness, nutrition and physical-mental health and gender differences among participants aged 16-18. A total of 263 volunteers participated in the study (123 males and 140 females). The three-factor eating questionnaire (TFEQ-18), SF-12 General Health Questionnaire and Body Awareness Questionnaire were used as data collection tools. For statistical analysis; Since the distribution is not normal, the Spearman Correlation Coefficient was used for correlation analysis and the Mann Whitney $U$ test was used to observe gender differences. We got a negative correlation between the male participants' uncontrolled eating score and mental health. In addition, a negative correlation was observed between the emotional eating variable and physical health in males, which measures the relationship between negative moods, such as loneliness, anxiety, or depressed mood, and over-eating. Female participants showed a weak correlation between body awareness and uncontrolled eating, body awareness and cognitive restraint, and body awareness and susceptibility to hunger. The difference between male and female participants for emotional eating was statistically significant. Our study indicates that acquiring healthy living habits at an early age will be the basis for the healthy adulthood process.

allow students to engage in moderate-to-vigorous physical activity not only can play an important role in health promotion but also encourages learning with fun (Lonsdale et al., 2013). At the same time, physical education lessons are an ideal setting to improve a child's fundamental movement skills and offer an opportunity to equip children with necessary fundamental movement skills and also contribute valuable physical activity time toward skills (van Beurden et al., 2003).

According to the World Health Organization, health is defined as a complete favor of physical, mental, and social well-being (WHO, 2013). The first assumption for maintaining a healthy life throughout life is to balance the body, mind, and soul. The second assumption is that an individual should take responsibility for improving the quality of life and develop healthy attitudes that will help to reach potential. From the first years of life, the process of being healthy will continue for a lifetime, and being a healthy individual increases the likelihood of success in life 
(Lyons et al., 2015). A person with a "healthy mind" has clear thoughts, the ability to solve the problems of daily life has good relations with friends, the family is mentally relaxed, and can bring happiness to her surroundings (Patel, 2003). Today, obesity is one of the most important threats to the health of adolescents. Worldwide, obesity rates have increased markedly in the last 50 years (Ogden et al., 2014; WHO, 2013). Being healthy and maintaining health physically and mentally at every stage of life is possible with adequate and balanced nutrition. Nutrition is essential for the protection of health as well as for the treatment of diseases. Today, nutrition is known to be crucial in the prevention of many chronic diseases such as cardiovascular diseases, many types of cancer, obesity, hypertension, diabetes, allergic diseases, osteoporosis, and dental caries. Chronic diseases generally threaten health in adulthood, but the foundations are laid in childhood and youth (Garibagaoglu et al., 2006). It is important to be aware of the changes in dietary habits and determine their relationship with health, for understanding the causes and consequences of dietary habits. Thus, it will be guided in making the necessary arrangements for a healthier and balanced diet of people. It is known that many mental health problems such as stress, anxiety, and depression are associated with being overweight and obese. Therefore, increasing mental health problems lead to decreased quality of life and negative health outcomes in individuals (Schur et al., 2013).

Body awareness involves focusing on and being aware of the internal senses of the body. The main purpose of determining physical awareness is to determine the correlation between emotional components and awareness of different parts of the body, to identify the disorders that occur in the normal functions of the body, and to understand the effect of the program implemented (Erden et al., 2013). Aware individuals are more competent in selfcompassion, auto control, willpower, and emotional regulation (Olson \& Emery, 2017). Nutritional awarenessbased interventions are intensive skills-based programs for the management of depression, stress, quality of life, and chronic pain by increasing well-being (Kabat-Zinn, 2009). These programs include interventions designed to manage obesity-related eating behaviors in many situations, such as reducing the desire for food intake, preventing emotional eating, stopping over-eating, and portion control (Olson \& Emery, 2017). According to the literature, it is clear that body awareness, nutrition, and health issues may be variables that affect and influence each other. Thus, this study aimed to determine the correlation between body awareness, nutrition, and health variables in adolescents.

\section{Materials and Methods:}

The survey method was the most general method within the descriptive research model, which is suitable for the purpose of the research and provides an exact picture of the existing situation with an economic process. This research is a descriptive type of cross-sectional study. It is a relational and comparative study.

A total of 263 adolescent participated in the study voluntarily, 123 males with a mean age of $16.95 \pm 1.19$ years, mean body length of $172.79 \pm 8.9 \mathrm{~cm}$ and mean body weight of $64.39 \pm 12.67 \mathrm{~kg}$ and 140 female with a mean age of $17.28 \pm 1.15 y$ years, mean body length of $162.67 \pm 6.81 \mathrm{~cm}$ and mean body weight of $53.72 \pm 7.74 \mathrm{~kg}$. Before the study, all participants were informed about the purpose of the study, and their parents have signed a voluntary consent form which was prepared according to Helsinki criteria.

Three-Factor Eating Questionnaire (TFEQ) was firstly developed by Stunkard \& Messick (1985), to measure the behavioral and cognitive components of eating as 51 questions and after the validity and reliability analysis, it was finalized with 18 questions (Stunkard \& Messick, 1985). After the validity and reliability analyze of the Turkish translation of the questionnaire, it was found that the reliability was high, and it measures the degree to which individuals consciously limit their eating, the level of uncontrolled eating, and the degree of emotional eating when they were emotional and also the Turkish version of the questionnaire measured the hunger sensitivity level (Kiraç et al., 2015). Yeomans \& McCrickerd (2017) reported that acute fasting may affect the results of a three-factor eating questionnaire, so data were collected half an hour after all participants had breakfast (Yeomans \& McCrickerd, 2017).

SF-12 is a questionnaire used to show the current health status of the society without focusing on a specif ic age and disease group (Kovacs et al., 2005). The questionnaire consists of sub-components of physical functionality, physical role, pain, general health, emotional role, mental health, social functioning, and vitality. No data was missing to evaluate the survey correctly. In order to make physical and mental standardization for each question, the values in the score table were used for all 12 items one by one. While 56,57706 was added to the total score of 12 questions for physical health scores, 60,75781 was added to the total score of 12 questions to determine mental health scores (Ware et al., 1996).

Body awareness questionnaire was developed by Shields et al., (1989) and the Turkish validity and reliability study was conducted by Karaca (2017) (Shields et al., 2010). The questionnaire consisted of 18 statements and four subgroups (changes in body process, sleep-wake cycle, prediction of onset of disease, prediction of body reactions). For each item, the scores between one and seven $(1=$ Not true for me - not correct, $7=$ Totally correct for me), and the final body awareness score is based on the total score. The higher the score, the better the awareness of the body. The normality analysis of the distribution was made and according to the Kolmogorov-Smirnov test, the distribution 
was not normal. For this reason, while the Spearman Correlation Coefficient was used for correlation analyzes, Mann-Whitney U Analysis was used to understand the genderdifferences.

\section{Results:}

There was a negative correlation between male participants' uncontrolled eating score and mental health $(\mathrm{r}=-.208)$. A high uncontrolled eating score indicates that the person tends to lose control over food when feeling hunger and is exposed to an external stimulus. In male participants, uncontrolled eating increases as mental health decreases. In addition, a negative correlation was observed in males between the emotional eating variable and physical health, which measures the relationship between negative moods, such as loneliness, anxiety, or depressed mood, and over-eating ( $\mathrm{r}=$-. 200). In female participants, there was a poor correlation between body awareness and uncontrolled eating ( $\mathrm{r}=-$. 215), body awareness and cognitive restraint $(\mathrm{r}=.174)$, and body awareness and susceptibility to hunger $(\mathrm{r}=-.235)$.

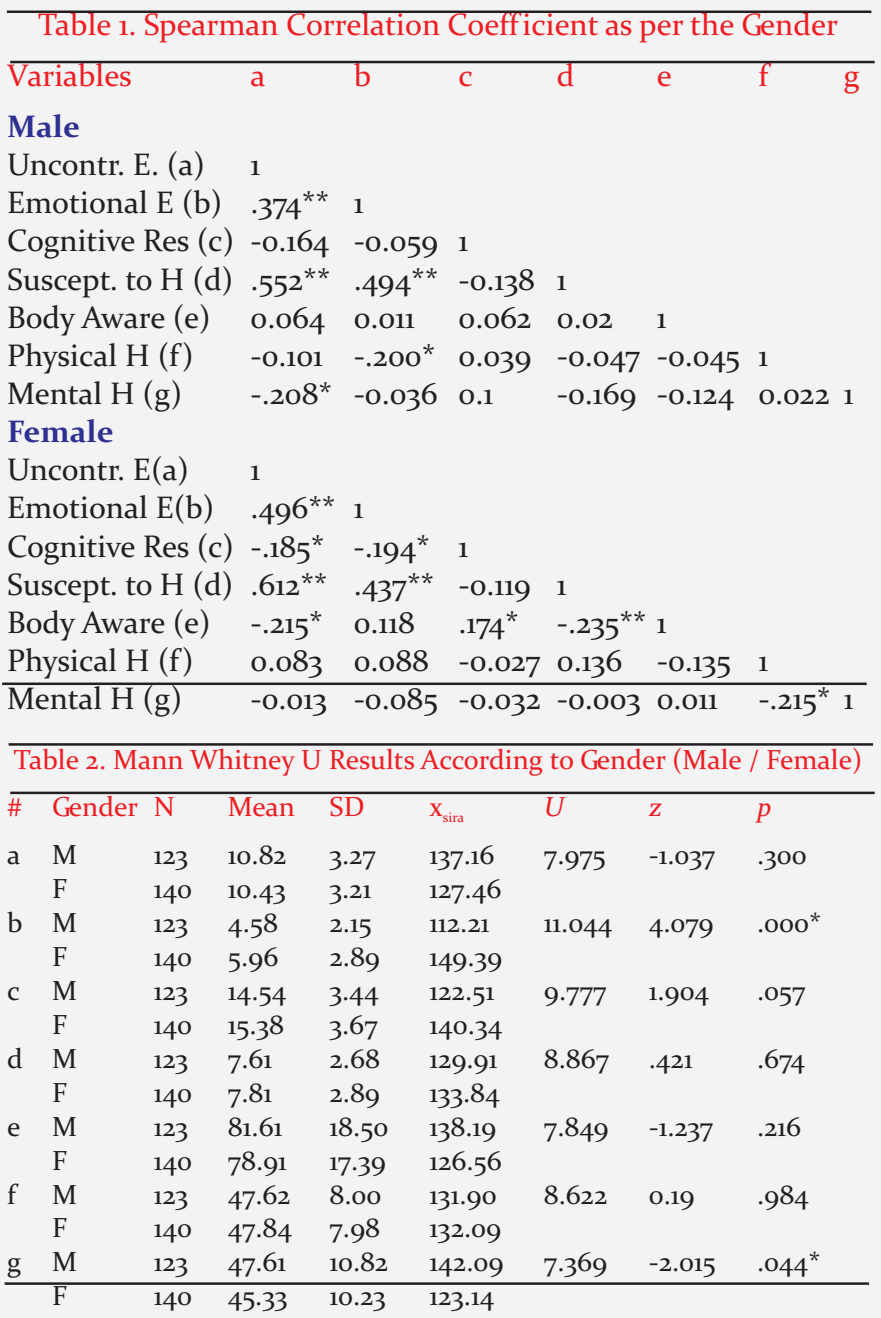

$\mathrm{a}=$ Uncontrolled Eating; $\mathrm{b}=$ Emotional Eating; $\mathrm{c}=$ Cognitive Restraint; $\mathrm{d}=$ Susceptibility to Hunger; e=Body Awareness; $\mathrm{f}=$ Physical Health; $\mathrm{g}=$ Mental Health
${ }^{*} \mathrm{p}<.05$

It was observed that the difference between male and female participants was statistically significant for the emotional eating variable, which measures the relation between negative mood, such as loneliness, anxiety, or depressed mood, and excessive eating ( $\mathrm{p}<.05)$. Emotional eating means a score of female participants was higher than males. The difference between male and female participants for the mental health variable was statistically significant and the results were in favour of the male participants (Table 2 ).

\section{Discussion:}

This study aimed to determine the correlation between body awareness, nutrition, and physical-mental health and gender differences among adolescents aged 16-18 years; according to the research results, as male mental health decreases, uncontrolled eating tendency increases, and a negative correlation was observed between emotional eating variable and physical health. Similarly; Ouwens et al. (2009) reported that high depressive symptoms were associated with emotional eating behaviors (Ouwens et al., 2009). Emotional and uncontrolled eating behaviors are also reported to be an important risk factor for individuals' ongoing body weight gain (Serin \& Şanlier, 2018). The difference between male and female participants for the mental health variable was statistically significant and the results were in favor of male participants. In adolescence, the prevalence of depression and eating disorders in girls has been reported in the literature (Parker \& Roy, 2001). Especially in early adolescence, women suffer more from internalizing disorders than men, which brings together depression and anxiety problems (Rosenfield \& Mouzon, 2012). When the differences according to gender are examined; the difference between male and female participants was statistically significant for an emotional eating variable $(\mathrm{p}<.05)$. The mean scores of emotional eating of female participants were higher than male participants. When the mean values of the three-factor eating questionnaire were examined in our study, it was seen that female participants had higher mean scores than male participants in the other three parameters except for the uncontrolled eating variable. Similarly; Löffler et al., (2015) reported that female participants had higher mean values than male participants in their study to determine age- and gender-specific norms of the three-factor eating questionnaire (Löffler et al., 2015).

In a study conducted with 409 participants, Arikan (2015) reported that female participants' eating habits were more affected by emotional state changes than male participants (Arikan, 2015). Children, adolescents, and obese individuals are defined as risk groups for emotional eating problemss (İnalkaç \& Arslantaş, 2018). Emotional eating is an eating disorder that is defined as a tendency to over-eat as a result of negative emotions. Individuals who 
exhibit emotional eating behavior may exhibit excessive eating behavior in moods such as anxiety, anger, and depression (Serin \& Șanlıer, 2018). Nguyen-Rodriguez et al., (2009) reported a significant correlation between emotional eating and perceived stress, anxiety, tension, and anxiety in female participants, while the only complex mood was reported to be associated with emotional eating in male participants (Nguyen-Rodriguez et al., 2009). Female participants showed a weak correlation between body awareness and uncontrolled eating-cognitive restraint-susceptibility to hunger. In this study, there was no statistically significant difference in body awareness scores between male and female participants. Similar to our study, Erden et al., (2013) reported that there was no significant difference between the genders in body awareness scores in a study conducted on healthy individuals (Erden et al., 2013). Similarly; Franzoi et al., (1989) studied with 40 women and 40 men, no statistical differences were observed depending on gender (Franzoi et al., 1989). In our study, uncontrolled eating decreases with increasing body awareness in female participants, and cognitive restraint increases with increasing body awareness. Similar to our study, Mehling et al., (2009) showed that increased body awareness affects the adaptation process of obese patients to life (Mehling et al., 2009). In our study, an emotional eating variable was associated with physical health in male participants; as emotional eating increases, physical health decreases. Emotional eating is a state of hunger that occurs even if the individual is full as a result of emotional triggers. Emotionally nourished individuals cannot distinguish whether their hunger is physiological or not. Emotions such as stress, anxiety, depression, and anger that cause emotional eating behavior generally increase food consumption and disrupt an individual's eating habits (Braden et al., 2018).

To develop the concepts of a healthy body and healthy mind, it is thought that besides being physically and mentally healthy, it will contribute to the increase of our quality of life-related to factors such as being aware of our body and paying attention to our diet. Acquiring healthy living habits at an early age will be the basis for the healthy adulthood process.

\section{Conclusion:}

Based on the findings of the study, it is suggested that; in general terms, it is observed that the emotional eating variable differs according to gender in adolescent children. Females are more affected by emotional states than males. In order to investigate the low-level relationships between body awareness and TFEQ in female participants, it is recommended to repeat the research with a larger group.

\section{References:}

Arikan, Z.Y. (2015): Eating behaviors of University students: A case of Dumlupinar University. Master of Science Thesis, Dumlupinar University, Natural and Applied Sciences Institute, Kütahya.

Braden, A., Musher-Eizenman, D., Watford, T. \& Emley, E. (2018): Eating when depressed, anxious, bored, or happy: are emotional eating types associated with unique psychological and physical health correlates? Appetite, 125:410-417.

CDC, (2010): Centers for Disease Control and Prevention: The association between school-based physical activity, including physical education, and academic performance

CDC, (2018): Centers for Disease Control and Prevention: Early care and education.

Dobbins, M., De Corby, K., Robeson, P., Husson, H. \& Tirilis, D. (2009): Programas escolares de actividad física para promover la actividad física y el buen estado físico en niños y adolescentes de entre seis y 18 años de edad (Revisión Cochrane traducida). Biblioteca Cochrane Plus, (2).

Erden, A., Altug, F. \& Cavlak, U. (2013): Investigation of the relationship between body awareness, pain, emotional status, and quality of life among healthy people. SCIE, 24(3):145-150.

Franzoi, S.L., Kessenich, J.J. \& Sugrue, P.A. (1989): Gender differences in the experience of body awareness: an experiential sampling study. Sex Roles, 21(7-8):499-515.

Garibagaoglu, M., Budak, N., Öner, N., Saglam, Ö. \& Nisli, K. (2006): The evaluation of nutritional status and body weights of female University students attending three different universities. L. Health Sci., 15(3):173-180.

Haywood, K.M. (1991): The role of physical education in the development of active lifestyles. Res. Quart. Exer. Sport, 62(2):151-156.

Inalkaç, S. \& Arslantas, H. (2018): Emotional eating. Arch. Med. Rev. L., $27(1): 70-82$.

Kabat-Zinn, J. (2009): Wherever You Go, There You Are: Mindfulness Meditation in Everyday Life. Pub. by: Hachette Books.

Karaca S. (2017): Turkish version of body awareness questionnaire: validity and reliability study. Master of Science Thesis. Mugla Sitki Koçman University, Mugla.

Khan, N.A., Raine, L.B., Donovan, S.M. \& Hillman, C.H. (2014): The relation of childhood physical activity to brain health, cognition, and scholastic achievement: IV. The cognitive implications of obesity and nutrition in childhood. Monogr. Soci. Res. Child Develop., 79(4):51-71.

Kiraç, D., Kaspar, E.Ç., Avcilar, T., Çakir, Ö.K., Ulucan, K., Kurtel, H., Deyneli, O. \& Güney A.I. (2015): A new method in investigation of obesity-related eating behaviors: threefactor eating questionnaire. L. Marmara Uni. Institute of Heal. Sci., 5(3):162-169.

Kovacs, F.M., Muriel, A. \& Abriaira, V. (2005): The influence of fear avoidance beliefs on disability and quality of life is sparse in spanish low back pain patients. Spine, 30(22):676-682.

Lonsdale, C., Rosenkranz, R.R., Peralta, L.R., Bennie, A., Fahey, P. \& Lubans, D.R. (2013): A systematic review and meta-analysis of interventions designed to increase moderate-to-vigorous physical activity in school physical education lessons. Prevent. 


\section{ORIGINAL ARTICLE}

Med., 56(2):152-161.

Löffler, A., Luck, T., Then, F.S., Luppa, M., Sikorski, C., Kovacs, P. et al. (2015): Age-and gender-specific norms for the german version of the three-factor eating-questionnaire (TFEQ) Appetite, 91: 241-247.

Lyons, S., Jackson, J. \& Hey, W. editors. (2015): Interactive Health and Fitness. A Practical Approach to Wellness. Pub. by: Sagamore Publishing. Urbana: Illinois.

Marshall, J. \& Hardman, K. (200o): The state and status of physical education in schools in international context. Eu. Phy. Edu. Rev., 6(3):203-229.

Mehling, W.E., Gopisetty, V., Daubenmier, J., Price, C.J., Hecht, F.M. \& Stewart, A. (2009): Body awareness: construct and self-report measures. PLoS One, 4(5):e5614.

Nguyen-Rodriguez, S.T., Unger, J.B. \& Spruift-Metz, D. (2009): Psychological determinants of emotional eating in adolescence. Eat Disord., 17:211-24.

Ogden, C.L., Carroll, M.D., Kit, B.K. \& Flegal, K.M. (2014): Prevalence of childhood and adult obesity in the United States, 2011-2012.Jama, 311(8):806-814.

Olson, K.L. \& Emery, C.F. (2015): Mindfulness and weight loss: A systematic review psychosomatic. Med., 77(1):59-67.

Ouwens, M.A., Van Strien, T., Van Leeuwe, J.F.J. \& Van der Staak, C.P.F. (2009): The dual pathway model of overeating. replication and extension with actual food consumption. Appetite, 52:234-237.

Parker, G. \& Roy, K. (2001): Adolescent depression: a review. Au. $N$ ZJPsychiat., 35:572-580.

Patel, V. (2003): Where there is no psychiatrist. Pub. by: London, England: Royal College of Psychiatrists.
Ambient Science, 2020: Vol. 07(Sp1); 180-184 DOI:10.21276/ambi.2020.07.sp1.oa23

Rosenf ield, S. \& Mouzon, D. (2012): Gender and Mental Health. In: Carol SA, Jo CP, Alex B, editors pp. 277-296. Handbook of the Sociology of Mental Health. Pub. by: Springer.

Schur, E., Godfrey, K.M. \& Dansie, E. (2013). Can familial factors account for the association of body mass index with poor mental health in men or women? Gen. Hosp. Psychiat., 35:502-507.

Serin, Y. \& Sanlier, N. (2018): Emotional eating, factors affecting food intake and basic nursing approaches. J. Psychiat. Nurs., 9(2):135-146.

Shields, S.A., Mallory, M.E. \& Simon, A. (1989): The body awareness questionnaire: Reliability and validity. J. Person. Asses., 53(4):802-815.

Stunkard, A.J. \& Messick, S. (1985): The three-factor eating questionnaire to measure dietary restraint, disinhibition and hunger.J. Psychosomat. Res., 29(1):71-83.

van Beurden, E., Barnett, L.M., Zask, A., Dietrich, U.C., Brooks, L.O. \& Beard, J. (2003): Can we skill and activate children through primary school physical education lessons? "Move it Groove it" a collaborative health promotion intervention. Preventive Med., 36(4):493-501.

Ware, J.E., Kosinski, M. \& Keller, S.D. (1996): A 12-item Short-Form Health Survey: construction of scales and preliminary test of reliability and validity. Med. Care, 34:220-233.

WHO (2013): Global strategy on diet, physical activity and health. 2013th ed. [document on the internet]. Geneva, Switzerland: World Health Organization.

Yeomans, M.R. \& McCrickerd, K. (2017): Acute hunger modifies responses on the three-factor eating questionnaire hunger and disinhibition, but not restraint scales. Appetite, 110:1-5. 